Published in "Flora 199: 70-81, 2004" which should

be cited to reference this work

\title{
Altitudinal differences in flower traits and reproductive allocation
}

\author{
Thomas Fabbro ${ }^{1, *}$, Christ ian Körner ${ }^{1}$ \\ 1 Institute of Botany, University of Basel, Schönbeinstrasse 6, CH-4056 Basel, Switzerland
}

Submitted: Jun 10, $2003 \cdot$ Accepted: Aug 1, 2003

\begin{abstract}
Summary
We tested whether alpine plants increase their effort to attract pollinators to compensate for assumed pollinator scarcity at high altitude. A three times larger fraction of the shoot was allocated to flowers in alpine plants (30 species, $2700 \mathrm{~m}$ asl) compared to lowland plants ( 20 species, $600 \mathrm{~m}$ asl), while leaf mass fraction did not differ between the altitudes. At high elevation, a three times smaller fraction of the shoot was allocated to stems, which was accompanied by a change in its function from leaf support for photosynthesis at low altitude to support for flowers at high altitude. Although shoot mass is massively reduced at high altitudes, display area and biomass of individual flowers were remarkably similar at both altitudes. All flowers together attracted pollinators with about the same total display area relative to overall plants size, but generally alpine plants maintain their flowers longer. Together with decreased plant height this leads to an increased self-shading which is likely to cause reductions in carbon gain in alpine plants. The results of this field survey emphasize the importance of outcrossing in alpine plants and its priority over growth.
\end{abstract}

Key words: alpine plant ecology, biomass, biometry, allometry, flower longevity, Swiss Alps

\section{Introduction}

The reduction in overall plant size is the most conspicuous structural alteration in plants observed along elevational gradients (Körner et al. 1989). Flower size does not seem to be affected in a proportional way and therefore alpine plant species are often believed to invest relatively more in reproductive structures.

Showy floral displays have evolved in many animal-pollinated plants as attractors to pollinators which mediate outcrossing (Proct or et al. 1996). Among alpine plant species, insect pollination is far more important than wind pollination and outcrossing appears to be the dominant breeding system (Körner 1999). Several studies of common alpine species revealed high genetic variability, indicating considerable outcrossing (see e.g. Bingham \& Ranker 2000; Gugerli 1998) which meets the expectation for population persistence in highly stochastic environments such as alpine habitats. This contradicts classical views predicting increasing self-compatibility, apogamy, polyploidy, and vegetative reproduction with increasing altitude, all of which tend to promote genetic uniformity of populations (Mosqu in 1966).
Pollinator preference for larger flowers or inflorescences has been demonstrated in a number of species belonging to a wide range of families and growing in different habitats (e.g. Schmid-Hempel \& Speiser 1988; Eckhart 1991; Ohara \& Higashi 1994; Conner \& Rush 1996; Thompson 2001). Higher rates of pollinator visitation provide fitness benefits due to greater pollen quantity or higher pollen quality or both. Furthermore plants with larger flowers may have greater reproductive success, because of earlier or more reliable pollen collection and deposition (Brody \& Mitchell 1997; Vaughton \& Ramsey 1998). Especially in extratropical mountains, the timing of pollination may be important because the growing season gets shorter with altitude and time for seed formation may be crucial (Wagner 1998).

Many studies around the world have documented reduced insect diversity, abundance, and activity in alpine ecosystems (see Bing ham \& Orthner 1998 for a review). More than 120 years ago this observation led Naegeli (cited in Müller 1881) to the following conclusion: "It is well known that alpine plants have larger and more intensively coloured flowers than lowland plants. There is no good explanation for this phenome-

* Corresponding author: Thomas Fabbro, Département de Biologie, Unité Ecologie \& Evolution, Chemin du Musée 10, CH-1700 Fribourg, Switzerland, e-Mail: thomas.fabbro@unifr.ch 
non. I suggest that the sparse insect abundance requires enhanced efforts for insect attraction. Only the largest and most shiny flowers will be fertilzed and will produce seeds, whereas at low elevation also medium sized flowers will have a chance to partcipate in the reproductive process" (translation from German).

Several other mechanisms could balance the presumed reduction in pollinator visitation rate at high altitude. Bingham \& Orthner (1998) demonstrated that a low pollinator visitation rate does not necessarily restrict pollination. They found comparable levels of pollination in alpine and foothill populations of Campanula rotundifolia and demonstrated that a lower pollinator diversity and activity at higher altitude were compensated for by longer stigmatic receptivity and the dominant role of bumblebees, which are very efficient pollinators. Evidence for inereased flower longevity at high altitude is provided by a comparison of Campanula species (Bl ion is et al. 2001) as well as community studies in Chile and New Zealand ( $\mathrm{Kal}$ in Arroyo 1981; Primack 1985). From comparing different habitats Pr ima ck (1985) concluded that flower longevity generally increased with cooler temperatures.

The current study aims at a quantitative test of some traditional views about enhanced display size and relative investment in reproductive structures in alpine versus low altitude herbaceous species belonging to comparable taxonomic groups and life forms in the Swiss Central Alps. However, the allocation of resources to flowers and their supportive structures represent only one part of the overall reproductive effort of plants. A complete account would have to include metabolic costs and costs associated with storage structures (Reekie \& Bazzaz 1987). Since earlier studies document that there are no elevational differences in relative investment in specific storage organs (Körner \& Renhardt 1987), we consider these other 'costs' as neutral in our comparison and focus on harvestable structures, namely peak growing season biometric data and biomass proportions. The observed patterns are compared relative to total above-ground shoot size in order to separate mere side-effects of the elevational decline of plant size from specific effects of altitude on reproductive structures.

\section{Materials and methods}

\section{Study sites and plant material}

A total of 50 different plant species each represented by $2-8$ individuals were collected at two different altitudes in Switzerland. 20 low altitude species were collected near Stein, Aargau $\left(47^{\circ} 34^{\prime} \mathrm{N}, 7^{\circ} 55^{\prime} \mathrm{E}\right)$ at $420 \mathrm{~m}$ asl in June 2001 and near Susten, Valais $\left(46^{\circ} 19^{\prime} \mathrm{N}, 7^{\circ} 39^{\prime} \mathrm{E}\right)$ at $600 \mathrm{~m}$ asl. In July and August of the same year 30 alpine species were sampled at about $2700 \mathrm{~m}$ asl in the Lämmerental, Valais $\left(46^{\circ} 24^{\prime} \mathrm{N}, 7^{\circ}\right.$ $\left.35^{\prime} \mathrm{E}\right)$ and near the Torrenthorn, Valais $\left(46^{\circ} 22^{\prime} \mathrm{N}, 7^{\circ} 40^{\prime} \mathrm{E}\right)$ in the Central Alps. Between the two altitudes mean air temperature in midsummer (July) declines from about $18^{\circ} \mathrm{C}$ to about $3^{\circ} \mathrm{C}$, which corresponds to a reduction in season length (daily mean air temperatures $>5^{\circ}$ ) from about 250 days at low altitude to about 50 days at high altitude (El 1 en ber g 1996). Calcareous rocks dominate the four locations but soil types differed considerably among locations and among microsites.

The replication unit for statistical analysis is the species (the mean of all individuals per species). Species were selected with the aim to compare ecologically, morphologically and taxonomically similar species from two contrasting altitudes (Table 1). To assure that ecologically comparable species were selected, ecological indicator values (Landolt 1977) were used. These values, similar to those by El l en berg (1991), rank species between 1 and 5 by their preference for specific soil and climate factors. Because all alpine species have a 'light value' > 3, low altitude species with a similar rank were selected, thus excluding species predominantly growing in shady places. Also species with 'humidity value' $<3$, growing typically in dry habitats, were excluded because they account for less then $2 \%$ of the alpine flora. The aim was to compare a broad spectrum of families represented by species from both altitudes. Because predominantly animal pollinated species were selected, some families were not represented though they occur in large numbers of species and individuals and account for a large fraction of biomass at both altitudes (e.g. Poaceae, Cyperaceae). The comparison was restricted to perennial herbaceous hemicryptophytes and geophytes, both well represented in the lowland and alpine flora. Phanerophytes and therophytes were excluded because they are very rare in the alpine flora and chamaephytes were excluded, because they account for only about $4 \%$ of species in the lowland flora.

All plants were collected in their natural habitat. Plants of the same species were taken from two different locations at the same altitude. Within each location samples were collected from different microsites. Only well developed and healthy looking plants at peak flowering time were used. Individuals with more than one flower were sampled when the number of simultaneously open flowers was at its maximum. Care was taken to select individuals that were representative with respect to any trait measured, i.e. "extreme" plant individuals (e.g. dwarfed plants) were excluded. In cases of clonal, multistemmed individuals the sampling unit was a ramet, also referred to as flowering shoot. To refer to the functional unit of pollination the term blossom sensu Faegri \& Van Der Pijl (1979) was used. It describes either an inflorescence (pseudanthium) or a flower (euanthium).

\section{Blossom traits}

In each plant individual the blossom buds, the open blossoms, and the withered blossoms were counted. The overall plant height was measured. Display area (A) was calculated as $A=\pi / 4 * d_{1} * d_{2}$, where $d_{1}$ is the largest and $d_{2}$ the smallest diameter (measured with a caliper to $0.1 \mathrm{~mm}$ accuracy) of each blossom. By multiplying display area $A$ with the number of simultaneously open blossoms the simultaneously presented 
Table 1. Selected plant species and their ecological indicator values, life form characteristics, and the number of individual plants collected. Nomencalture follows (Lauber \& Wagn er 1996).

\begin{tabular}{|c|c|c|c|c|c|c|c|}
\hline $\begin{array}{l}\text { High altitude } \\
\text { Species (number of individuals) }\end{array}$ & $H^{a}$ & $N^{a}$ & $L^{a}$ & \multicolumn{4}{|l|}{ Low altitude } \\
\hline Apiaceae & & & & Apiaceae & & & \\
\hline Ligusticum mutellinoides (6) & 3 & 2 & 5 & Heracleum sphondylium (3) & 3 & 4 & 3 \\
\hline Asteraceae & & & & Asteraceae & & & \\
\hline Achilla nana (3) & 3 & 2 & 5 & Achillea millefolium* ${ }^{*}(2)$ & 2 & 3 & 4 \\
\hline Aster alpinus* (6) & 2 & 2 & 5 & Bellis perennis* $(2)$ & 3 & 4 & 4 \\
\hline Doronicum grandiflorum* $(6)$ & 3 & 3 & 5 & Carduus crispus (3) & 3 & 5 & 4 \\
\hline Erigeron glabratus* (7) & 2 & 2 & 5 & Leucanthemum vulgare*(2) & 3 & 3 & 4 \\
\hline Homogyne alpina* (7) & 3 & 2 & 3 & Senecio erucifolium* (3) & 2 & 3 & 4 \\
\hline Leontodon helveticus* (6) & 3 & 2 & 4 & Campanulaceae & & & \\
\hline Leucanthemopsis alpina* (6) & 3 & 2 & 5 & Campanula trachelium* (3) & 3 & 3 & 2 \\
\hline Taraxacum officinale*(4) & 3 & 4 & 4 & Dipsacaceae & & & \\
\hline Boraginaceae & & & & Knautia arvensis* (3) & 2 & 3 & 4 \\
\hline Myosotis alpestris* (6) & 3 & 3 & 4 & Fabaceae & & & \\
\hline Brassicaceae & & & & Lathyrus pratensis $*(3)^{b}$ & 3 & 3 & 3 \\
\hline Pritzelago alpina* $(6)$ & 4 & 2 & 4 & Lotus corniculatus* $(2)$ & 2 & 3 & 4 \\
\hline Campanulaceae & & & & Trifolium medium (3) & 2 & 3 & 3 \\
\hline Campanula scheuchzeri*(6) & 3 & 3 & 4 & Trifolium pratense* $(5)$ & 3 & 3 & 3 \\
\hline Phyteuma hemisphaericum* (6) & 3 & 2 & 4 & Trifolium repens (5) & 3 & 4 & 4 \\
\hline Fabaceae & & & & Lamiaceae & & & \\
\hline Lotus alpinus* (6) & 3 & 3 & 4 & Prunella vulgaris*(3) & 3 & 3 & 4 \\
\hline Trifolium badium (3) & 3 & 3 & 4 & Ranunculaceae & & & \\
\hline Gentianaceae & & & & Ranunculus acris (2) & 3 & 4 & 3 \\
\hline Gentiana campestris* (3) & 3 & 2 & 4 & Ranunculus polyanthemophyllus* (3) & 3 & 4 & 3 \\
\hline Gentiana clusii* (3) & 2 & 2 & 5 & Ranunculus tuberosus* (3) & 3 & 2 & 3 \\
\hline Gentiana orbicularis* (4) & 3 & 2 & 5 & Rosaceae & & & \\
\hline Gentiana verna* (4) & 3 & 2 & 4 & Potentilla erecta* ${ }^{*}(2)$ & 3 & 2 & 4 \\
\hline Liliaceae & & & & Scrophulariaceae & & & \\
\hline Lloydia serotina $*(8)^{b}$ & 2 & 1 & 4 & Veronica chamaedrys* $(2)^{b}$ & 3 & 4 & 3 \\
\hline Orchidaceae & & & & Valerianaceae & & & \\
\hline Nigritella nigra $(6)^{b}$ & 3 & 2 & 4 & Valeriana officinalis* (3) & 4 & 4 & 3 \\
\hline Primulaceae & & & & Mean (low altitude species) & 2.9 & 3.5 & 3.5 \\
\hline $\begin{array}{l}\text { Androsace chamaejasme* (6) } \\
\text { Ranunculaceae }\end{array}$ & 2 & 2 & 4 & & & & \\
\hline Ranunculus alpestris* (6) & 4 & 2 & 4 & & & & \\
\hline Ranunculus glacialis* (6) & 3 & 2 & 4 & & & & \\
\hline Ranunculus montanus* (6) & 3 & 4 & 3 & & & & \\
\hline Rosaceae & & & & & & & \\
\hline Geum montanum* (7) & 3 & 2 & 4 & & & & \\
\hline Rubiaceae & & & & & & & \\
\hline Galium megalospermum* (5) & 3 & 2 & 4 & & & & \\
\hline Scrophulariaceae & & & & & & & \\
\hline Pedicularis verticillata* (3) & 4 & 2 & 4 & & & & \\
\hline Veronica aphylla* (7) & 3 & 2 & 4 & & & & \\
\hline Violaceae & & & & & & & \\
\hline Viola calcarata* $(6)$ & 3 & 2 & 5 & & & & \\
\hline Mean (high altitude species) & 2.9 & 2.3 & 4.2 & & & & \\
\hline
\end{tabular}

${ }^{a}$ Indicator values after Landol t (1977) for humidity $H$ and nutrient level $N$ of the soil and for light $L$ availability $(1=$ lowest, $5=$ highest preference).

${ }^{b}$ Geophytes (all other species are hemicryptophytes)

* Subset of species discussed in Table 3 . 
display area was calculated. Total display area, which will be presented in one season, was calculated by multiplying display area A with the total number of blossoms. One representative blossom of each plant was dried and weighed.

Differences in blossom mass and display area between high and low altitude species were tested by analysis of variance (ANOVA). Whether the increase in display area with increasing blossom mass changed with altitude was tested by allometric scaling analysis as described below. In the analysis, blossom mass was used as covariate and altitude and the interaction between altitude and blossom mass were used as explanatory factors.

The difference in total blossom number per flowering shoot between altitudes was tested by a generalized linear model (Proc genmod, SAS ver. 8.2, SAS Institute, Cary, NC), because the data were expected to be Poisson distributed. Altitudinal differences in the fraction of simultaneously open blossoms (open blossoms divided by total blossom number) was tested by ANOVA after arcsin square root transformation. Whether the display area of all simultaneously open blossoms and the total display area of all blossoms presented in one season differed between elevations was tested by ANOVA.

To compare flower longevity of alpine species with literature data from different lowland habitats (see Pr ima ck 1985 for a review), the longevity of individual blossoms was measured in 24 alpine species. Individual blossom buds were marked with a little plastic tag at both alpine sites. The number of days an individual blossom remained open with a freshly appearing perianth in the field was counted by observing the tagged blossoms every second day in the early afternoon. Plants were not protected against herbivores and a considerable number of flowers was browsed during the observation period. Because the chance of a blossom becoming browsed increased with observation time, the observed blossom longevities are likely to underestimate the true blossom longevities but are nonetheless informative.

\section{Relationship between blossoms and plant size}

Above-ground shoots were separated into a flower, a stem, and a leaf fraction. The flower fraction contains all flowers including their involucrum, whereas stems and flower stalks form the stem fraction and the leaves with their petioles included form the leaf fraction. Fractions were weighed after $48 \mathrm{~h}$ oven drying at $80^{\circ} \mathrm{C}$.

Typical alpine and lowland species differ considerably in their overall plant size (Schroeter 1926; Körner et al. 1989). It is therefore important to test if an observed altitudinal difference with respect to any trait is merely a side-effect of the overall size difference rather than a 'true' effect of the altitudinal difference. The size-dependent behaviour of various systems is evaluated by means of allometric scaling analysis (Nikl a s 1994). A change in size without a change in geometry and shape is called an isometric change. The opposite, an allometric change, describes a size-dependent departure of geometry or shape. The analysis of size-related variability requires an appropriate mathematical function which adequately describes the observed data. When the variable of interest varies across several magnitudes, which is typical for interspecies comparisons, the power function equation is most commonly used:

$$
Y=\alpha X^{\beta}
$$

where $\mathrm{Y}$ is the variable of particular interest, $\mathrm{X}$ is the variable measuring size, $\alpha$ is the scaling (or regression) coefficient, and $\beta$ is the scaling (or regression) exponent. The power function equation can easily be linearized by log-transformation:

$$
\log _{10} Y=\log _{10} \alpha+\beta \log _{10} X
$$

In a log $-\log$ plot the scaling exponent $(\beta)$ represents the slope and the logarithm of the scaling coefficient $\left(\log _{10} \alpha\right)$ the intercept of the regression of $\log _{10} Y$ on $\log _{10} X$.

Isometric scaling means that the $Y / X$-ratio is independent of size $(X)$. If $Y$ and $X$ are measured in the same dimension, the null-hypothesis of isometry is $\beta=1$. If $Y$ has the dimension of an area and $X$ the dimension of a weight, then the null-hypothesis of isometry is $\beta=2 / 3$, and if $Y$ has the dimension of an area and $X$ the dimension of distance, the null-hypothesis of isometry is $\beta=2$ (see Nikl as 1994 for further information). The null-hypothesis of isometry $(\beta=b)$ was tested with a t-test:

$$
\mathrm{t}=\frac{\hat{\beta}-b}{S_{\hat{\beta}}} \sim t_{n-2}
$$

where $\hat{\beta}$ is the estimate (based on the sample) of the true value of $\beta$ in the population, $s_{\hat{\beta}}$ is the standard deviation of $\hat{\beta}$, and $n$ is the number of ${ }^{\beta}$ species. Differences in $\alpha$ and $\beta$ between altitudes were tested by analysis of covariance (ANCOVA). Type I sums of squares were used to sequentially evaluate the effect of size $\left(\log _{10} X\right)$, altitude and the interaction between altitude and size. A significant effect of altitude indicated that the intercept $\left(\log _{10} \alpha\right)$ of the allometric regression line changed with altitude. A change in the slope of the allometric regression line $(\beta)$ was indicated by a significant interaction between altitude and the covariate. For a significant altitudinal effect $\left(\begin{array}{ll}\alpha_{\text {high }} & \alpha_{\text {low }}\end{array}\right)$ three cases can be distinguished:

1. The slops differ between the altitudes $\left(\begin{array}{ll}\beta_{\text {high }} & \beta_{\text {low }}\end{array}\right)$ : The altitudinal effect depends on size $(X)$ and therefore can not be interpreted independent of size.

2. The slopes do not differ between the altitudes $\left(\beta_{\text {high }}=\beta_{\text {low }}\right)$ but $Y$ scales anisometric with size $(X)\left(\begin{array}{ll}\beta & 1\end{array}\right)$ :

The altitudinal effect depends on size $(X)$ but with a constant difference between the two $\log _{10}$-curves.

3. The slopes do not differ between the altitudes $\left(\beta_{\text {high }}=\beta_{\text {low }}\right)$ and $Y$ scales isometric with size $(X)(\beta=1)$ :

Only in this case the altitudinal effect is independent of size $(X)$.

The method of allometric scaling as described above was used to analyse the relative contributions of leaf, stem and flower mass to above-ground shoot mass and to extrapolated total plant mass (shoot/root ratios estimated by Körner \& Renhardt (1987) for alpine and lowland species were used). The same model was also used to test the allometric 
scaling of flower mass, and stem mass versus leaf mass. Also the total floral display area in relation to above-ground shoot mass, leaf mass and overall plant height was analysed by allometric scaling.

Self-shading by flowers is most obvious in compact cushion plants. Therefore two common alpine cushion species (Androsace alpina and Silene acaulis) were used to assess the reduction in photon flux density (PFD) at leaf level caused by the expanded flowers. These cushion plant data represent an estimate of the maximum self-shading effect. At two different alpine locations between 2600 and $2800 \mathrm{~m}$ asl a total of six individual cushions of Silene acaulis and three individual cushions of Androsace alpina were selected at the time of peak flowering in July 2001. All flowers within a $4 \mathrm{~cm}$ diameter area were cut off and arranged exactly in the same orientation on a self-adhesive transparency. A PFD-sensor was positioned $2 \mathrm{~cm}$ below the transparency in a dark box. At different radiation intensities (depending on weather conditions) repeated readings $(\mathrm{n}=10)$ for transparency only and transparency with flowers were taken (plus readings with the unobscured sensor).

\section{Results}

\section{Blossom traits}

Display area and biomass of individual blossoms did not differ significantly between lowland and alpine species (Table 2). Neither simple flowers nor pseudanthia differed significantly in display area or biomass between altitudes. There was a strong correlation between display area and biomass of individual blossoms at both altitudes $\left(p<0.001, R^{2}=0.779\right.$, Fig. 1$)$ and no anisometric sealing of display area with increasing blossom mass was detected at both altitudes. This means that for individual blossoms the area/biomass-ratio is independent of blossom mass. Also when species with simple flowers only $(p=0.602)$ or Asteraceae with pseudanthia only $(p=0.571)$ were considered, display area per blossom mass did not significantly differ between altitudes. In other words, plants allocate a similar amount of biomass per display area to individual blossoms and a similar
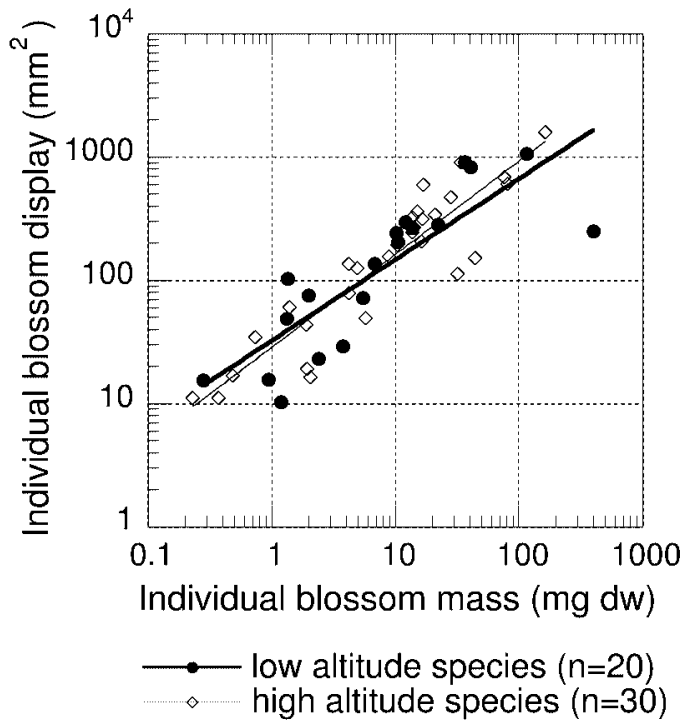

Fig. 1. Relationship between display area and biomass of individual blossoms: Neither intercepts nor slopes differed between altitudes ( $p>0.4$ in both cases) and at both altitudes scaling did not differ from isometry $\left(H_{0}: \beta=0.667\right.$, $p>0.4$ in both cases).

biomass fraction within blossoms is allocated to display structures at both altitudes.

The number of blossoms per individual or ramet of alpine species with simple flowers was on average 7 times smaller than for lowland species (Table 3 ). For species with pseudanthia the blossom number of alpine species was even 31 times smaller. At high altitude, the mean total display area of individual plants was 7 times smaller for species with simple flowers and 22 times smaller for species with pseudanthia.

About $50 \%$ of the investigated alpine species had only one blossom per season compared to $15 \%$ of the lowland species.

At the time of peak flowering, the fraction of simultaneously open blossoms of all blossoms was larger for alpine species. For species with simple flowers the

Table 2. Display area and biomass of individual blossoms from alpine and lowland species (mean $\pm 1 \mathrm{SE}, \mathrm{n}$ : number of investigated species)

\begin{tabular}{lcrlrl}
\hline & low altitude & (n) & high altitude & (n) & $p$-value \\
\hline $\begin{array}{l}\text { display area }\left(\mathrm{mm}^{2}\right) \\
\text { simple flowers }\end{array}$ & & & & & \\
pseudanthia (Asteraceae) & $221 \pm 84$ & $(15)$ & $179 \pm 40$ & $(22)$ & 0.622 \\
all blossoms together & $254 \pm 152$ & $(5)$ & $554 \pm 185$ & $(8)$ & 0.446 \\
biomass (mg) & & $(20)$ & $279 \pm 63$ & $(30)$ & 0.782 \\
$\begin{array}{l}\text { simple flowers } \\
\text { pseudanthia (Asteraceae) }\end{array}$ & $14.7 \pm 7.8$ & $(15)$ & $11.5 \pm 3.8$ & $(22)$ & 0.690 \\
all blossoms together & $56.6 \pm 41.1$ & $(20)$ & $22.4 \pm 6.5$ & $(8)$ & 0.322 \\
\end{tabular}


Table 3. Whole plant blossom traits of lowland and alpine species (mean $\pm 1 \mathrm{SE}, \mathrm{n}$ : number of investigated species).

\begin{tabular}{|c|c|c|c|c|c|}
\hline & low altitude & (n) & high altitude & (n) & $p$-value \\
\hline \multicolumn{6}{|l|}{ number per plant ${ }^{\mathrm{a}}$} \\
\hline simple flowers & $69 \pm 44$ & (14) & $9.2 \pm 2.8$ & $(21)$ & $<0.001$ \\
\hline pseudanthia (Asteraceae) & $59 \pm 35$ & (5) & $1.9 \pm 0.8$ & (8) & $<0.001$ \\
\hline all blossoms together & $67 \pm 33$ & (19) & $7.2 \pm 2.1$ & $(29)$ & $<0.001$ \\
\hline \multicolumn{6}{|c|}{ fraction simoultaneously open ${ }^{\mathrm{b}}$} \\
\hline simple flowers & $0.47 \pm 0.02$ & (11) & $0.92 \pm 0.01$ & (19) & 0.002 \\
\hline pseudanthia (Asteraceae) & $0.83 \pm 0.07$ & (4) & $1.00 \pm 0.00$ & (7) & 0.113 \\
\hline all blossoms together & $0.58 \pm 0.02$ & $(15)$ & $0.95 \pm 0.00$ & $(26)$ & $<0.001$ \\
\hline \multicolumn{6}{|l|}{ total display area $\left(\mathrm{cm}^{2}\right)$} \\
\hline simple flowers & $37 \pm 15$ & (14) & $5.0 \pm 1.1$ & (21) & 0.015 \\
\hline pseudanthia (Asteraceae) & $151 \pm 102$ & (5) & $6.9 \pm 2.2$ & $(8)$ & 0.093 \\
\hline all blossoms together & $67 \pm 29$ & (19) & $5.5 \pm 1.0$ & $(29)$ & 0.013 \\
\hline \multicolumn{6}{|c|}{ display area simultaneously open ${ }^{\mathrm{b}}\left(\mathrm{cm}^{2}\right)$} \\
\hline simple flowers & $10.3 \pm 5.5$ & $(11)$ & $3.5 \pm 0.8$ & (19) & 0.117 \\
\hline pseudanthia (Asteraceae) & $33.6 \pm 28.5$ & (4) & $6.3 \pm 2.0$ & (7) & 0.222 \\
\hline all blossoms together & $16.5 \pm 8.3$ & (15) & $4.2 \pm 0.8$ & (26) & 0.061 \\
\hline
\end{tabular}

a No data available for the Apiaceae (Heraclum sphondylium at low and Ligusticum mutellinoides at high altitude.

b The investigated species are marked with $(*)$ in Table 1 .

Table 4. Blossom longevity of 20 alpine species in days.

\begin{tabular}{|c|c|c|c|}
\hline family & species (blossom/plant number) & mean & range \\
\hline \multirow[t]{2}{*}{ Asteraceae } & Homogyne alpina $(1 / 1)$ & 13.0 & \\
\hline & Leontodon helveticus $(2 / 2)$ & 10.5 & $10-11$ \\
\hline \multirow[t]{4}{*}{ Brassicaceae } & Arabis alpina $(1 / 1)$ & 5.0 & \\
\hline & Draba aizoides (12/4) & 8.1 & $4-11$ \\
\hline & Pritzelago alpina (44/6) & 4.9 & $3-8$ \\
\hline & Thlaspi rotundifolia $(7 / 1)$ & 9.0 & $9-9$ \\
\hline Campanulaceae & Campanula scheucherzi (1/1) & 9.0 & \\
\hline \multirow[t]{2}{*}{ Caryophyllaceae } & Cerastium latifolium (1/1) & 8.0 & \\
\hline & Silene acaulis (3/3) & 6.5 & $5-12$ \\
\hline \multirow[t]{2}{*}{ Gentianaceae } & Gentiana clusii (5/2) & 8.0 & $8-8$ \\
\hline & Gentiana verna $(3 / 3)$ & 8.7 & $5-11$ \\
\hline Ranunculaceae & Ranunculus alpestris (2/2) & 9.5 & $6-10$ \\
\hline Rosaceae & Geum reptans $(6 / 2)$ & 11.0 & $10-12$ \\
\hline Rubiaceae & Galium megalospermum (3/1) & 10.0 & $10-10$ \\
\hline \multirow[t]{4}{*}{ Saxifragaceae } & Saxifraga androsace $(14 / 7)$ & 8.1 & $4-15$ \\
\hline & Saxifraga bryoides (1/1) & 5.0 & \\
\hline & Saxifraga oppositifolia (19/4) & 6.6 & $5-10$ \\
\hline & Saxifraga paniculata $(4 / 2)$ & 16.0 & $12-18$ \\
\hline Scrophulariaceae & Veronica aphylla $(15 / 5)$ & 4.2 & $1-8$ \\
\hline Violaceae & Viola calcarata $(2 / 2)$ & 13.5 & $11-16$ \\
\hline all species together (mean $\pm 1 \mathrm{SE}$ ) & & $8.7 \pm 0.7$ & \\
\hline \multicolumn{4}{|c|}{ Comparable data on flower longevity (Pr imack 1985) } \\
\hline Chilean montane ${ }^{\mathrm{a}}$ (24 species) & & 4.2 & $1-15$ \\
\hline Chilean subalpine $^{b}$ ( 9 species) & & 6.9 & $4-12$ \\
\hline Temperate forest ${ }^{\mathrm{c}}$ (32 species) & & 5.7 & $1-14$ \\
\hline Prairie $^{\mathrm{d}}(10$ species $)$ & & 2 & $1-4$ \\
\hline
\end{tabular}

a Simple flowers, summer dry shrubland or upper mattoral $(2000 \mathrm{~m}$ asl $)$

b Dry, rocky Andean habitat (3500 m asl)

c Early summer flora in forest, canopy gaps, fields, and roadsides $(1200 \mathrm{~m}$ asl)

${ }^{\mathrm{d}}$ Herbaceous plants 
fraction of simultaneously open blossoms almost doubled, whereas the difference was not significant for species with pseudanthia. However, since only flowering individuals were collected, these results depend on the total number of blossoms per individual plant which decreased with altitude. In alpine species, the mean display area of simultaneously open blossoms tended to be about 4 times smaller whereas the mean of the total seasonal display area was about 12 times smaller than in low altitude species.

Mean longevity of individual blossoms of 20 alpine species was 8.7 ( $\pm 0.7 \mathrm{SE}$ ) days (Table 4). Mean longevity of Asteraceae pseudanthia alone (11.5 days) was longer than the mean longevity of simple flowers $(8.5$ days). The longest period of flowering in a single blossom was observed in one Erigeron glabratus which, unfortunately, could not be observed until senescence, because the blossom was consumed by animals after 28 days of continuous flowering. Similarly blossoms of Leontopodium helveticum were browsed after 21 days of continuous flowering and blossoms of Doronicum grandiflorum after 18 days of continuous flowering. Flowers of Veronica aphylla had the shortest mean longevity with only 4.2 days.

\section{Relationship between blossoms and plant size}

The above-ground shoot mass of low and high altitude species varied over several orders of magnitude (Fig. 2). On average flowering individuals of alpine species weighed $97 \pm 18.0 \mathrm{mg}$ while lowland species had mean individual/ramet weights of $4690 \pm 2040 \mathrm{mg}$, i.e. were 48 times heavier. However, mean flower mass fraction (flower mass/total shoot mass) was nearly three times larger in alpine than in lowland species (Fig. 3 and 4). The stem mass fraction differed in the opposite direction and was three times smaller at high than at low altitude. The leaf mass fraction of shoots did not differ significantly between altitudes. At both altitudes neither flower, stem, nor leaf mass fraction changed significantly with increasing above-ground shoot mass. In other words, the flower, stem, and leaf mass scaled isometrically with above-ground shoot mass at both altitudes. Between altitudes, allometric scaling of flower, stem, and leaf mass versus above-ground shoot mass did not significantly differ, demonstrating that the observed differences in flower and stem mass fraction between altitudes were not a side-effect of the overall difference in above-ground shoot mass between altitudes but represent true altitude effects on allocation.

The extrapolation from measured above-ground shoot mass to the total plant mass (using the shoot/root ratios by Körner \& Renhardt (1987)) changed only the intercepts but not the slopes of the regression lines.
Similar to the shoot-only data, total plant flower mass fraction was larger than at low altitude $(p<0.001)$, stem mass fraction was smaller at high than at low altitude $(p<0.001)$, and leaf mass fraction remained the same at both altitudes $(p=0.496)$.

Relative to leaf mass, alpine species tended to have a 2.2 times larger flower mass than lowland species $(p=0.067)$. The allometric scaling of flower mass versus leaf mass did not significantly differ between altitudes $(p=0.191)$. Within low elevation species, flower mass scaled isometrically with leaf mass (Ho: $\beta=0.667, p=0.438$ ) but within high elevation species flower/leaf biomass-ratio decreased with increasing leaf mass $\left(H_{0}: \beta=0.667, \mathrm{p}=0.039\right)$. The overall stem/leaf mass-ratio was 3.2 times smaller at high than at low altitude $(\mathrm{p}<0.001)$, but this relationship was not independent of leaf mass. At high altitude stem mass increased less with increasing leaf mass than at low altitude $(p=0.010)$, thus the difference in stem/leaf mass-ratio increased with leaf mass. Whereas the stem/leaf mass-ratio of alpine species decreased with increasing leaf mass $(p=0.010)$, stem/leaf massratio of lowland species scaled isometric $(p=0.826)$.

Considering the regressions on leaf mass and comparing the slopes of alpine and lowland species with each other revealed a very conspicuous pattern. The flower/leaf mass-ratio and the stem/leaf mass-ratio of alpine species decreased with increasing leaf mass whereas the same ratios of lowland species sealed isometric. This means that the larger an alpine plant becomes, measured as an increase in leaf mass, the smaller is the relative allocation to flowers or stems.

Relative to their above-ground shoot mass there was no significant difference in the total floral display area between lowland and alpine species (Fig. 5). Also in the increase of display area with increasing above-ground shoot mass there was no difference between the altitudes.

Total floral display area per leaf mass did not significantly differ between altitudes $(p=0.880)$, but at low altitude the increase of floral display area with increasing leaf mass was significantly more pronounced than at high altitude $(p=0.014)$. Within high altitude species the ratio between floral display area and leaf mass scaled anisometric and decreased with increasing leaf mass $\left(H_{0}: 0=0.667, p=0.041\right)$. At low altitude, the ratio between display area and leaf mass was independent of leaf biomass $\left(H_{0}: \beta=0.667, p=0.957\right)$.

Relative to plant height alpine species showed larger floral display areas $(p=0.050)$, but this difference depended on plant height $(p=0.039)$. The altitudinal difference in total floral display area between low and high altitude species decreased with plant height. At low altitude display area scaled isometrie with plant height 


\section{Low altitude species:}

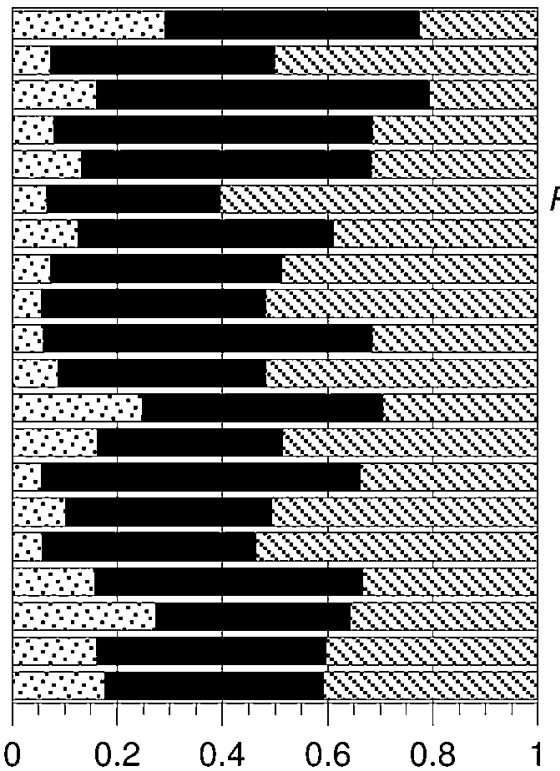

Carduus crispus

Heracleum sphondylium

Senecio erucifolium

Valeriana officinalis

Campanula trachelium

Ranunculus polyanthemophyllus Knautia arvensis

Ranunculus acris

Lathyrus pratensis

Achillea millefolium

Ranunculus tuberosus

Trifolium pratense

Trifolium medium

Lotus corniculatus

Trifolium repens

Potentilla erecta

Leucanthemum vulgare

Prunella vulgaris

Veronica chamaedris

Bellis perennis

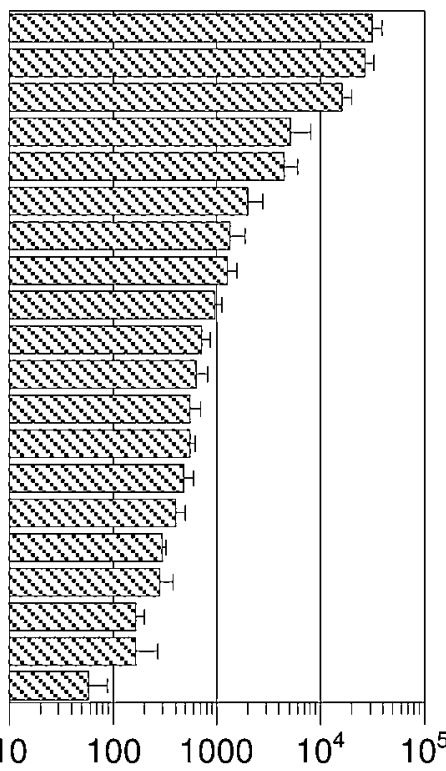

High altitude species:



Doronicum grandiflorum Gentiana clusii

Taraxacum officinale

Geum montanum

Homogyne alpina

Nigritella nigra

Aster alpinus

Pedicularis verticillata

Leontodon helveticus

Ranunculus glacialis

Ligusticum mutellinoides

Achillea nana

Erigeron glabratus

Gentiana campestris

Ranunculus alpestris

Ranunculus montanus

Myosotis alpestris

Lotus alpinus

Campanula scheuchzeri

Veronica aphylla

Leucanthemopsis alpina

Trifolium badium

Viola calcarata

Gentiana verna

Phyteuma hemisphaericum Gentiana orbicularis

Lloydia serotina

Galium megalospermum

Androsace chamaejasme

Pritzelago alpina
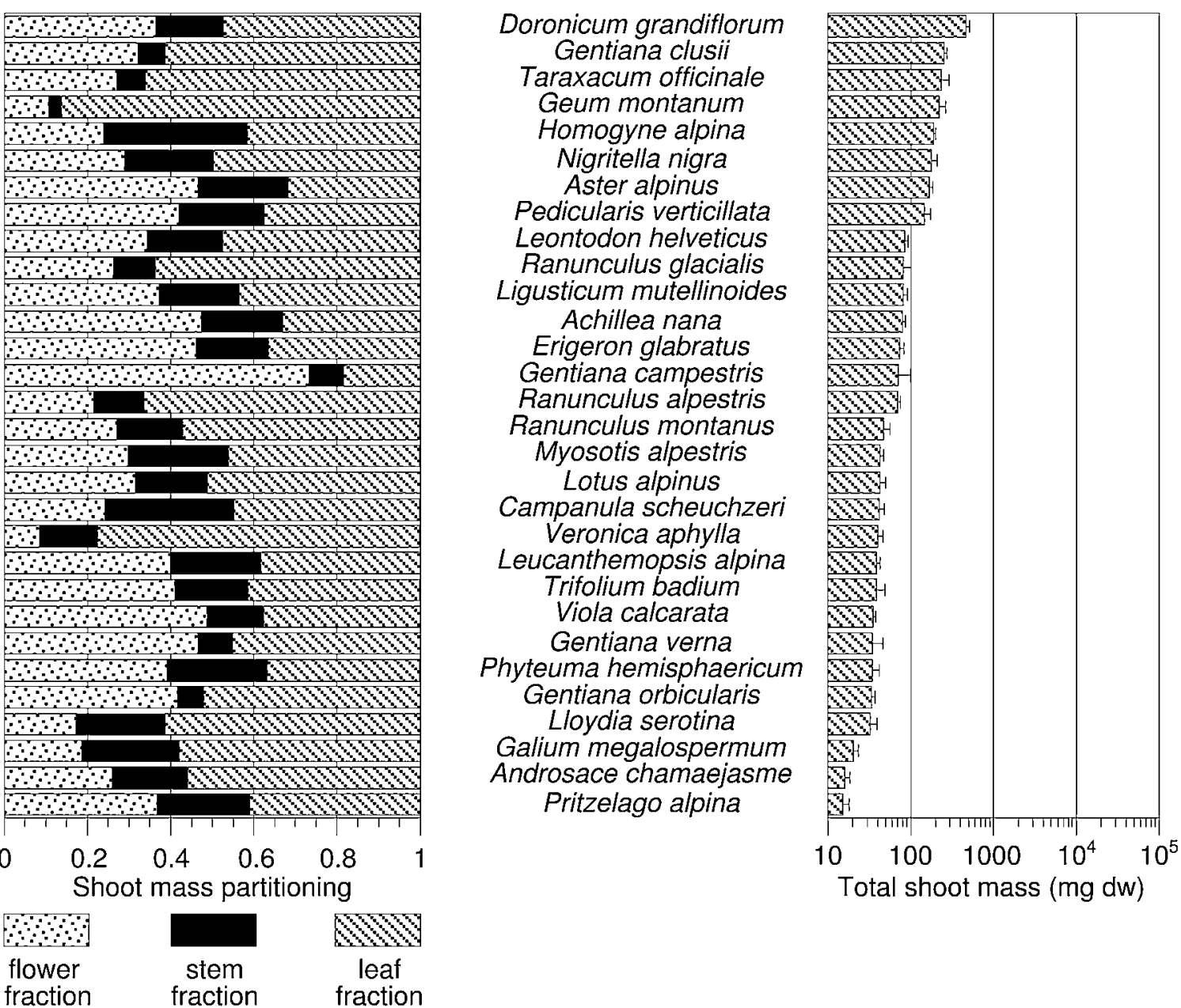

Total shoot mass (mg dw)

Fig. 2. Shoot mass partitioning and above-ground biomass (mean + SE) of 20 low and 30 high altitude species. 


\section{Low altitude species}
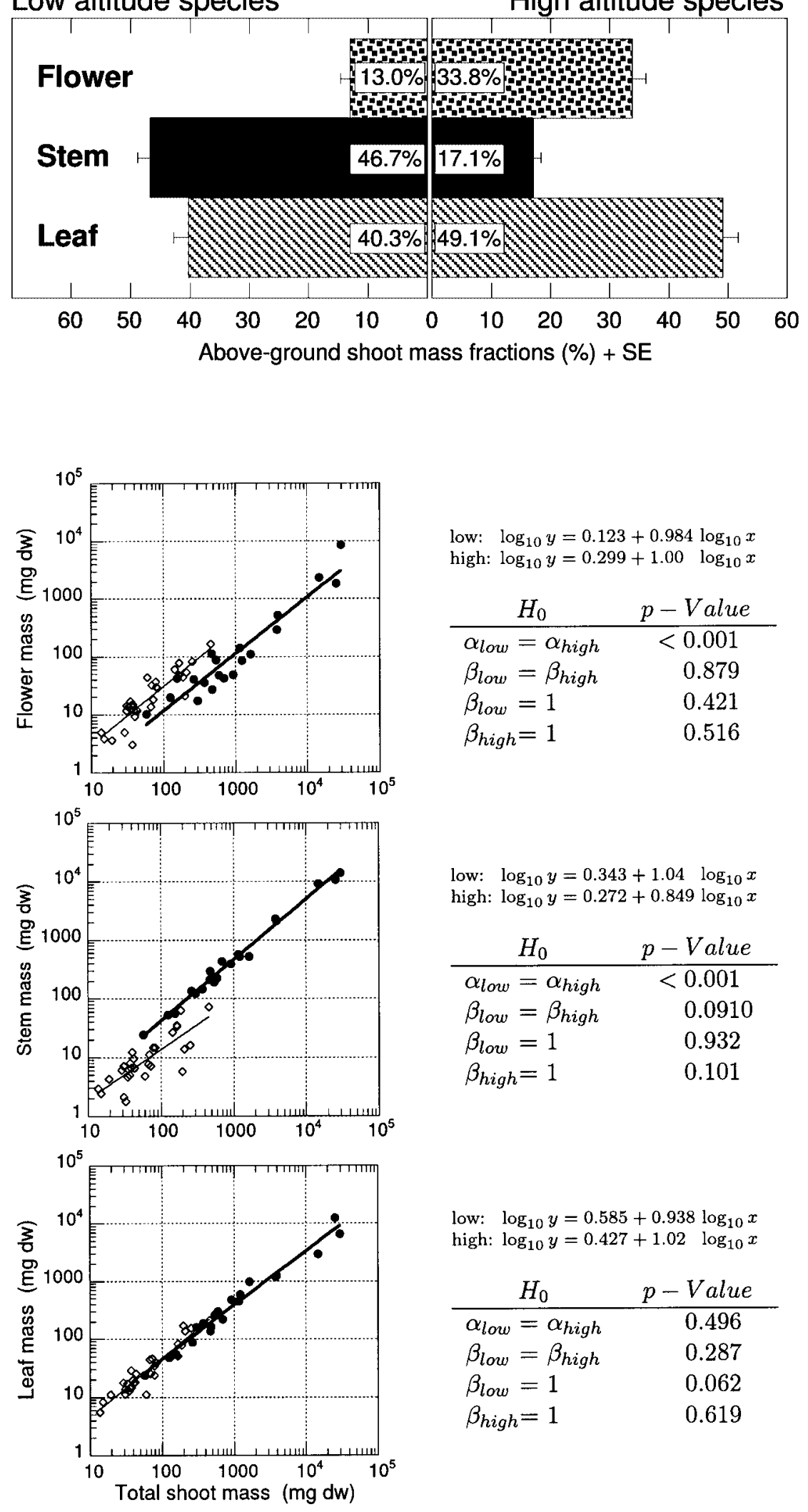

$\because$ low altitude species $(n=20)$ high altitude species $(n=30)$ low: $\log _{10} y=0.123+0.984 \log _{10} x$ high: $\log _{10} y=0.299+1.00 \log _{10} x$

\begin{tabular}{cr}
$H_{0}$ & $p-$ Value \\
\hline$\alpha_{\text {low }}=\alpha_{\text {high }}$ & $<0.001$ \\
$\beta_{\text {low }}=\beta_{\text {high }}$ & 0.879 \\
$\beta_{\text {low }}=1$ & 0.421 \\
$\beta_{\text {high }}=1$ & 0.516
\end{tabular}

low: $\log _{10} y=0.343+1.04 \log _{10} x$ high: $\log _{10} y=0.272+0.849 \log _{10} x$

\begin{tabular}{cc}
$H_{0}$ & $p-$ Value \\
\hline$\alpha_{\text {low }}=\alpha_{\text {high }}$ & $<0.001$ \\
$\beta_{\text {low }}=\beta_{\text {high }}$ & 0.0910 \\
$\beta_{\text {low }}=1$ & 0.932 \\
$\beta_{\text {high }}=1$ & 0.101
\end{tabular}

low: $\log _{10} y=0.585+0.938 \log _{10} x$ high: $\log _{10} y=0.427+1.02 \log _{10} x$

\begin{tabular}{cc}
$H_{0}$ & $p-$ Value \\
\hline$\alpha_{\text {low }}=\alpha_{\text {high }}$ & 0.496 \\
$\beta_{\text {low }}=\beta_{\text {high }}$ & 0.287 \\
$\beta_{\text {low }}=1$ & 0.062 \\
$\beta_{\text {high }}=1$ & 0.619
\end{tabular}

Fig. 3. Mean shoot mass partitioning of 30 high altitude species and 20 low altitude species.
Fig. 4. Relationship between flower, stem, and leaf mass with above-ground shoot mass: Regression equations and $p$-values for testing whether intercepts $(\alpha)$ and slopes $(\beta)$ differ between altitudes and whether allometric scaling at both altitudes differs significantly from isometriy $\left(H_{0}: \beta=1\right)$. 


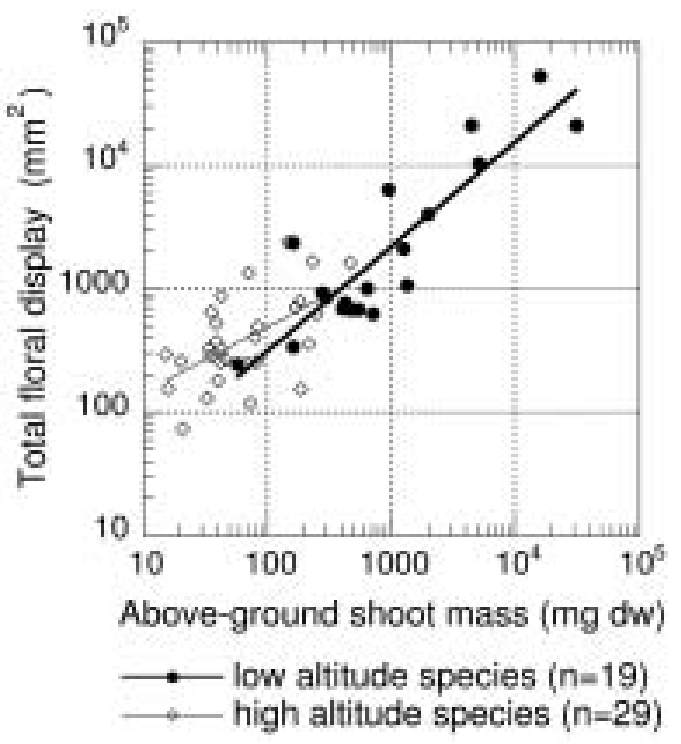

Fig 5. Relationship between display area and above-ground shoot mass: Neither intercepts $(p=0.278)$ nor slopes ( $p=0.106)$ differed between altitudes and at both altitudes scaling did not differ from isometry $\left(H_{0}: \beta=0.667, p>0.2\right.$ in both cases).

$\left(H_{0}: \beta=2, p=0.278\right)$, but at high altitude display area increased less with plant height $\left(H_{0}: \beta=2\right.$, $p=0.001)$.

\section{Self-shading by flowers in alpine species}

In Silene acaulis on average $72 \%$ (ranging from 51-83\%) and in Androsace alpina on average $75 \%$ (ranging from $73-90 \%$ ) of the photon flux density (PFD) was absorbed by the flowers which are expanded directly above the leaves. Assuming a growing season length of about 50 days and a flower longevity of about 6.5 days for these two species (Table 4), this corresponds to a $10 \%$ reduction of the whole season photon flux density available to the leaves.

\section{Discussion}

High altitude species allocated three times more of their above-ground biomass to floral structures than lowland species. Relative to leaf mass the allocation to floral structures was still more than doubled in high altitude species compared to low altitude species. This change clearly indicates the importance of outcrossing in alpine species. While the shoot mass fraction allocated to stems decreased in alpine species, the function of stems changes from leaf support for photosynthetic light capture at low altitude to almost exclusive support for flowers at high altitude. Whereas lowland species have about half of their leaves inserted on reproductive stems, high altitude species have only a few if any leaves (about one fourth) on stems (Kör n er et al. 1989). The remarkably similar fraction of above-ground biomass allocated to leaves over the large altitudinal range studied confirms earlier findings by Körner \& Renhardt (1987).

In contrast to the massively reduced shoot mass and height of alpine plants, dry-weight and mean display area of individual blossoms did not differ from lowland species. A comparison in nine Campanula species along an altitudinal gradient in Greece revealed the same pattern. Neither corolla width nor corolla depth changed with elevation (Bl ion is et al. 2001). The overall change in pollinator spectrum with altitude (see e.g. Müll er 1881; Kal in Arroyo et al. 1982) does not seem to result in a general altitudinal change of blossom size.

This is remarkable given the considerable altitudinal change in habitat structure and knowing that single plant populations ean adapt flower size rapidly to changes in the pollinator assemblage of different altitudes (Galen 1996).

Whereas floral size traits do not seem to change with altitude, several studies show that the longevity of individual flowers increases with altitude (Primack 1985; Bingham \& Orthner 1998; Bl ion is et al. 2001; Bl io$\mathrm{n}$ is \& Vok ou 2002). The 8.3 days of flower longevity in the 18 alpine species with simple flowers was even longer than the 6.9 days reported for high Andean species in Central Chile (4.2 days at low altitude), and slightly longer than the 7.8 days (5.9 days at low altitude) found in subalpine species in New Zealand (Primack 1985).

At the level of single blossoms, the data presented in this study suggests that the assumed pollinator scarcity at high altitude is somewhat compensated by a prolonged longevity of individual blossoms rather than by enlarged display area of individual blossoms. There are several hypothetical reasons for prolonged flower longevity in alpine species. First, elevational increase of cloud cover (Kör n er 1999) frequently reduces temperatures below the minimum for pollinator flight. Second, because many alpine species have only one flower, geitonogamy (pollination by pollen from another flower on the same plant) is prevented and does not select against longer flowering (Harder \& Barret $t$ 1995). Third, water availability is commonly better in alpine than in lowland habitats which may permit prolonged flowering (Gal en et al. 1999).

The increase in flower longevity and the constancy of proportional floral display demonstrate that the overall effort to attract pollinators is larger in high altitude species than in lowland species. In a seminal paper, Haig \& West oby (1988) proposed that "natural selection may often act to bring the female's allocation of her repro- 
ductive effort to a point where seed production is limited by both pollen supply and provisioning resources". Results of several field studies confirmed this hypothesis and suggest that simultaneous constraints from pollen availability and other environmental factors are common in natural populations (see Tot 1 and 2001). The enhanced investment in pollinator attraction in alpine species suggests that alpine plants can take advantage of the increased pollinator service. This suggests that alpine plants have enough resources to allocate more above-ground biomass to flowers, maintain the flowers longer, and still have enough resources for adequate seed production. It also implies a clear prioritising of reproduction over growth (photosynthesis) at high altitude. This is probably facilitated by the known high photosynthetic capacity and common carbon surplus found in alpine plants (Körner \& Diemer 1987). The massiv self-shading of some alpine species by flowers further underlines that these plants do not prioritise carbon gain. Because display area relative to leaf mass does not change and flowering stalks get shorter with increasing altitude, the likelihood of selfshading is generally increased at high altitude. The more plants attach to the ground, the more they decouple their climate from the ambient, and the higher the heat accumulation in the leaf canopy (Körner 1999). This reduction of plant height in alpine species may also have a positive effect on flower temperature which may increase seed set and the attractiveness for pollinators. The effect of plant architecture on heat accumulation could be far more significant than the effect of flower heliotropism. The latter could not be shown to influence plant fitness, although flowers were found slightly warmer (Tot 1 an d 1996). In cold alpine environments a warm flower environment due to short flower stalks could substitute the advantage of taller plants, which were shown to attract more pollinators (Donnelly \& Lort ie 1998).

In conclusion, the importance of sexual reproduction in alpine environments is emphasized by the increased allocation of biomass to structures of sexual reproduction. The effort of high altitude species to attract pollinators was increased by prolonged flowering at a similar proportional display area compared to low altitude species. Reproductive allocation seems to be prioritised over maximisation of growth in alpine species.

\section{References}

Bingham, R. A. \& Orthner, A.R. (1998): Efficient pollination of alpine plants. - Nature 391: 238-239.

Bingham, R. A. \& Ranker, T. A. (2000): Genetic diversity in alpine and foothill populations of Campanula rotundifolia (Campanulaceae). - Int. J. Plant Sci. 161: 403-411.
Bl ion is, G. J. \& Vokou, D. (2002): Structural and functional divergence of Campanula spatulata subspecies on Mt Olympos (Greece). - Plant Syst. Evol. 232: 89-105.

Bl ion is, G. J.; Hal l ey, J. M. \& Vokou, D. (2001): Flowering phenology of Campanula on Mt Olympos, Greece. Ecography 24: 696-706.

Brody, A. K. \& Mit chel1, R. J. (1997): Effects of experimental manipulation of inflorescence size on pollination and pre-dispersal seed predation in the hummingbirdpollinated plant Ipomopsis aggregata. - Oecologia 110: 86-93.

Conner, J. \& Rush, S. (1996): Effects of flower size and number on pollinator visitation to wild radish, Raphanus raphanistrum. - Oecologia 105: 509-516.

Donnelly, S. E. \& Lort ie, C. J. (1998): Pollination in Verbaseum thapsus (Scrophulariaceae): the advantage of being tall. - Am. J. Bot. 85: 1618-1625.

Eckhart, V.M. (1991): The effects of floral display on pollinator visitation vary among populations of Phacelia linearis (Hydrophyllaceae). - Evol. Ecol. 5: 370-381.

El 1 en ber g, H. (1991): Indicator values for plants in Central Europe. - Seripta Geobotanica 18: 1-248.

El l enberg, H. (1996): Vegetation Mitteleuropas mit den Alpen in kausaler, dynamischer und historischer Sicht. Ulmer, Stuttgart.

Faegri, K. \& van der Pijl, L. (1979): The principles of pollination ecology. - Pergamon, Oxford.

Gal en, C. (1996): Rates of floral evolution: Adaptation to bumblebee pollination in an alpine wildflower, Polemonium viscosum. Evolution 50: 120-125.

Galen, C.; Sherry, R.A. \& Carroll, A. B. (1999): Are flowers physiological sinks or faucets? Costs and correlates of water use by flowers of Polemonium viscosum. Oecologia 118: 461-470.

Gucerli, F. (1998): Effect of elevation on sexual reproduction in alpine populations of Saxifraga oppositifolia (Saxifragareae). - Oecologia 114: 60-66.

Haig, D. \& West oby, M. (1988): On limits to seed production. - Am. Nat. 131: 757-759.

Harder, L. D. \& Barret t, S.C.H. (1995): Mating cost of large floral displays in hermaphrodite plants. - Nature 373: $512-515$.

Kal in Arroyo, M. T. (1981): Plant phenological patterns in the high Andean Cordillera of central Chile. - J. Ecol. 69: 205-223.

Kal in Arroyo, M. T.; Primack, R. \& Armest o, J. J. (1982): Community studies in pollination ecology in the high temperate Andes of central Chile 1. Pollination mechanisms and altitudinal variation. - Am. J. Bot. 69: 82-97.

Kör ner, Ch . (1999): Alpine plant life. - Springer, Berlin.

Körner, Ch . \& Diemer, M. (1987): In situ photosynthetic responses to light, temperature and carbon dioxide in herbaceous plants from low and high altitude. Funct Ecol 1: 179-194.

Körner, CH. \& Renhardt, U. (1987): Dry matter partitioning and root lenth/leaf area ratios in herbaceous perennial plants with diverse altitudinal distribution. - Oecologia 74: 411-418 
Körner, Ch.; Neumayer, M.; Menendez-Riedl, S.P. \& Smeet s-Scheel, A. (1989): Functional morphology of mountain plants. - Flora 182: 353-383.

Lan dol t , E. (1977): Ökologische Zeigerwerte zur Schweizer Flora. - Veröff. Geobot. Inst. ETH, Stiftung Rübel, Zürich 64: 1-207.

Lauber, K. \& Wagner, G. (1996): Flora Helvetica. - Haupt, Bern.

Mosqu in, T. (1966): Reproductive specialization as a factor in the evolution of the Canadian flora. In: Tayl or, R. L. \& Ludwig, R. A. (eds) The evolution of Canada's flora. University of Toronto press, Toronto 41-63.

Müller, H. (1881): Alpenblumen, ihre Befruchtung durch Insekten und ihre Anpassungen an dieselben. - Engelmann, Leipzig.

Nikl as, K. (1994): Plant allometry: the scaling of form and process. - The University of Chicago Press, Chicago.

Ohara, M. \& Higashi, S. (1994): Effects of inflorescence size on visits from pollinators and seed set of Corydalis ambigua (Papaveraceae). - Oecologia 98: $25-30$.

Primack, R. (1985): Longevity of individual flowers. - Annu. Rev. Ecol. Syst. 16: 15-37.

Proct or, M.; Ye o, P. \& Lack, A. (1996): The natural history of Pollination. - Timber Press, Portland.

Reekie, E. G. \& Bazzaz, F. A. (1987): Reproductive effort in plants. 1. Carbon allocation to reproduction. - Am. Nat. 129: $876-896$

Sch mid-Hempel, P. \& Speiser, B. (1988): Effects of inflorescence size on pollination in Epilobium angustifolium. Oikos 53: 98-104.

Schroet er, C. (1926): Das Pflanzenleben der Alpen. Eine Schilderung der Hochgebirgsflora. - Raustein, Zürich.

Thompson, J.D. (2001): How do visitation patterns vary among pollinators in relation to floral display and floral design in a generalist pollination system? - Oecologia 126: $386-394$

Tot 1 and, O. (1996): Flower heliotropism in an alpine population of Ranunculus acris (Ranunculaceae): Effects on flower temperature, insect visitation, and seed production. - Am. J. Bot. 83: 452-458.

Tot 1 and, O. (2001): Environment-dependent pollen limitation and selection on floral traits in an alpine species. Ecology 82: 2233-2244.

Vau ght on, G. \& Ra msey, M . (1998): Floral display, pollinator visitation and reproductive success in the dioecious perennial herb Wurmbea dioica (Liliaceae). - Oecologia 115: $93-101$.

Wagn er, J. (1998): Phenology, seed development, and reproductive success of an alpine population of Gentianella germanica in climatically varying years. - Bot. Acta 111: $159-166$ 